J. Dairy Sci. 97:2591-2599

http://dx.doi.org/10.3168/jds.2013-7593

(C) American Dairy Science Association ${ }^{\circledR}, 2014$.

\title{
Development of a locally sustainable functional food based on mutandabota, a traditional food in southern Africa
}

\author{
Augustine Mpofu, ${ }^{\star} † \ddagger$ Anita R. Linnemann,† Wilbert Sybesma,§ Remco Kort,§\#ll M. J. R. Nout,† \\ and Eddy J. Smid $\ddagger^{1}$ \\ *Department of Food Science and Technology, Chinhoyi University of Technology, P. Bag 7724 Chinhoyi, Zimbabwe \\ †Food Quality and Design, and \\ łLaboratory of Food Microbiology, Wageningen University, Bornse Weilanden 9, 6708 WG, Wageningen, the Netherlands \\ §Yoba for Life Foundation, Hunzestraat 133-A, 1079 WB, Amsterdam, the Netherlands \\ \#Molecular Cell Physiology, VU University Amsterdam, De Boelelaan 1085, NL-1081 HV, Amsterdam, the Netherlands \\ IITNO Microbiology and Systems Biology, PO Box 360, 3700 AJ, Zeist, the Netherlands
}

\begin{abstract}
A probiotic dairy product was developed on the basis of a traditional dish called mutandabota to enable resource-poor populations in southern Africa to benefit from a functional food. Mutandabota is widely consumed in rural southern Africa, making it an ideal food matrix to carry probiotics. First, a process to produce probiotic mutandabota was designed. Raw cow milk was boiled and subsequently cooled to ambient temperature $\left(25^{\circ} \mathrm{C}\right)$. Next, dry pulp from the fruit of the baobab tree (Adansonia digitata L.) was added to the milk at a concentration of $4 \%$ (wt/vol). This mixture was inoculated with the probiotic Lactobacillus rhamnosus yoba and left to ferment for $24 \mathrm{~h}$, while the growth of the bacterial culture was monitored. Final ingredients were then added to produce probiotic mutandabota that had $14 \%$ (wt/vol) baobab fruit pulp and $7 \%$ (wt/vol) sugar in cow milk. The $\mathrm{pH}$ of probiotic mutandabota was $\mathrm{pH} 3.5$, which ensures that the product is microbiologically safe. The viable plate count of L. rhamnosus yoba increased from $5.8 \pm 0.3 \mathrm{log} \mathrm{cfu} /$ $\mathrm{mL}$ at the point of inoculation to $8.8 \pm 0.4 \log \mathrm{cfu} /$ $\mathrm{mL}$ at the moment of consumption, thereby meeting the criterion to have a viable count of the probiotic bacterium in excess of $6 \log \mathrm{cfu} / \mathrm{mL}$ of a product. Baobab fruit pulp at $4 \%$ promoted growth of L. rhamnosus yoba with a maximal specific growth rate $\left(\mu_{\max }\right)$ of 0.6 $\pm 0.2 / \mathrm{h}$ at $30^{\circ} \mathrm{C}$. The developed technology, though specific for this particular product, has potential to be applied for the delivery of probiotics through a variety of indigenous foods in different regions of the world. Upon consumption, probiotic mutandabota is expected to improve the population's intestinal health, which is
\end{abstract}

Received October 11, 2013.

Accepted January 22, 2014.

${ }^{1}$ Corresponding author: eddy.smid@wur.nl especially relevant for vulnerable target groups such as children and elderly people.

Key words: Lactobacillus rhamnosus, milk, baobab fruit, probiotic mutandabota

\section{INTRODUCTION}

Ingestion of probiotics is associated with health benefits (FAO/WHO, 2001; Lacroix and Mollet, 2007). To date, enhancing health and nutrition by provision of probiotics to less-affluent communities in a locally sustainable way is still a major challenge. The use of indigenous foods as potential vehicles for transmission of probiotics has been given little attention even though it is an option with great potential in developing countries. Indigenous foods are made from locally available resources. These traditional foods not only have a long history of safe use, they can also be afforded by the local communities. Mutandabota is one such indigenous food product known in southern Africa (Ministry of Agriculture, 2001). It is particularly popular in Zimbabwe and has potential for use as a probiotic carrier. It is made at a household level by mixing raw milk from cows or goats and dry baobab (Adansonia digitata L.) fruit pulp (Ministry of Agriculture, 2001; Mpofu et al., 2014). Mutandabota is considered a source of proteins and other micronutrients in southern Africa, where it is consumed as breakfast or lunch on a daily basis. The ingredients of mutandabota are $79 \%$ (wt/wt) milk, $14 \%$ (wt/wt) baobab fruit pulp, and 7\% (wt/wt) crystalline sucrose (Mpofu et al., 2014).

The Food and Agriculture Organization of the United Nations/World Health Organization (FAO/ WHO, 2001) defines probiotics as live microorganisms that, when consumed in adequate amounts as part of food, confer a health benefit to the host. This definition emphasizes that first, probiotics must be consumed in a food matrix that allows them to survive passage through the stomach and exposure to bile, and second, 
a product should contain a certain number of viable probiotic cells that has been shown to deliver a health benefit. Although no cell-count level is recognized to guarantee a health effect (Reid, 2008), a minimum level of $6 \mathrm{log} \mathrm{cfu} / \mathrm{g}$ of product is needed for a product to be considered probiotic (Shah, 2000; Adikhari et al., 2003). Studies on probiotic bacteria with higher (Gionchetti et al., 2007) or lower (Whorwell et al., 2006) viable cell counts have been published. The viable cell count of the probiotic bacteria is critical in the evaluation of the quality and functionality of a probiotic food product. Guandalini et al. (2000) demonstrated the beneficial effect of Lactobacillus rhamnosus GG on children suffering acute, watery diarrhea. In this study, children 1 mo to $3 \mathrm{yr}$ of age, presenting recent onset of acute diarrhea, were enrolled in a double-blinded and placebo-controlled intervention trial. They concluded that the administration of $L$. rhamnosus GG in the oral rehydration solution to children with diarrhea was safe and resulted in marked and significant shorter duration of diarrhea, less chance of a protracted course, and faster discharge from the hospital.

Lactobacillus rhamnosus GG is one of the most thoroughly studied probiotics (Kankainen et al., 2009; von Ossowski et al., 2010; Kort and Sybesma, 2012). It is a lactic acid bacterium that meets the United Nations standard for probiotics and the requirements for clinical trial documentation (FAO/WHO, 2001). Evidence exists of beneficial effects of $L$. rhamnosus GG for prevention and treatment of antibiotic-associated diarrhea (Ruszczynski et al., 2008), rotavirus diarrhea (Grandy et al., 2010), gastrointestinal and upper respiratory tract infections in children (Hojsak et al., 2010) and inhibiting growth and adhesion of enteropathogens (Mack et al., 1999; Gopal et al., 2001). Lactobacillus rhamnosus GG shows a high tolerance to the acidic conditions prevailing in the stomach (Tuomola et al., 2000; Corcoran et al., 2005), survives intestinal passage (Sandholm-Mattila et al., 1999), is able to adhere to human colonic mucosa (Alander et al., 1999; Rinkinen et al., 2003), and transiently colonizes the gastrointestinal tract after treatment (Sandholm-Mattila et al., 1999; Tuomola et al., 2000).

In southern Africa, probiotic foods are scarce and expensive. They are not consumed by the rural population, in which lack of hygiene, poor sanitation, malnutrition, and enteric infections frequently lead to diarrheal disorders (Olivieri et al., 2008; Food and Nutrition Council, 2010). This study was meant to facilitate access of the rural population to the benefits of probiotics. To produce probiotic mutandabota in a sustainable way, a strategy was developed based on 2 main considerations. First, mutandabota is a nonfermented dairy product, which takes less than half an hour to prepare (Mpofu et al., 2014). It is consumed within an hour after preparation. The easiest way to provide probiotics through this food would be to add the appropriate quantity of the probiotic to mutandabota just before consumption. This option, however, would require large quantities of the probiotic and was thus considered costly, unsustainable, and beyond the reach of the targeted communities. A second option is to have one producer in the village who would propagate the probiotic to produce an inoculum to be distributed to other villagers, who would, in turn, use the inoculum to produce their own probiotic mutandabota. Because commercially produced media for propagating probiotics are beyond the reach of the target population, locally available resources such as full-fat milk from local cows and indigenous baobab fruit pulp were considered in this study as the propagation medium. This study describes the development of a probiotic variant of mutandabota as a sustainable, nutritious, and healthpromoting food produced at the village level.

\section{MATERIALS AND METHODS}

\section{Extraction of Baobab Fruit Pulp}

Mature, dry baobab fruits were collected from the wild in Binga district, Zimbabwe. Baobab fruits ripen and dry out while they are still on trees. Harvesting is done by gathering the dropping, dry fruits from the ground. To extract pulp, fruits were cracked by hitting them against a hard surface such as a rock. The dry pulp together with seeds was separated from the pericarps. Pulp was then separated from seeds by sieving and collected in a winnowing basket for preparation of mutandabota.

\section{Medium and Inoculum for Probiotic Mutandabota}

A strain of $L$. rhamnosus GG under the name $L$. rhamnosus yoba (Kort and Sybesma, 2012) was used throughout this study. The strain was obtained from Yoba for Life Foundation, Amsterdam, the Netherlands. It was stored at $-80^{\circ} \mathrm{C}$ before being freeze-dried for long-term storage at $4^{\circ} \mathrm{C}$ in $50-\mathrm{mL}$ tubes (Greiner Bio-One BV, Alphen a/d Rijn, the Netherlands). Lactobacillus rhamnosus GG grows slowly in milk (Hekmat and Reid, 2007; Valík et al., 2008). Glucose or another appropriate fermentable sugar is usually added to stimulate growth (Jyoti et al., 2003; Gaudreau et al., 2005). In southern Africa, these substrates have to be imported in most cases, which implies extra costs to production. In this study, locally available baobab fruit pulp was added to full-fat cow milk that had been boiled and subsequently cooled to ambient temperature 
$\left(25^{\circ} \mathrm{C}\right)$ before using it to cultivate $L$. rhamnosus yoba. The appropriate quantity of baobab fruit pulp for the medium was determined by adding pulp to milk at different concentrations and observing the $\mathrm{pH}$ changes and the subsequent growth abilities of the bacterium. Lactobacillus rhamnosus yoba was precultured in this medium in a fermentation vessel and incubated at $37^{\circ} \mathrm{C}$ for $36 \mathrm{~h}$ to a level exceeding $9 \log \mathrm{cfu} / \mathrm{mL}$. This culture was used for producing probiotic mutandabota.

\section{Determination of the Growth Rate of L. rhamnosus Yoba}

The growth rate of L. rhamnosus yoba in heat-treated full-fat cow milk supplemented with $4 \%$ (wt/vol) baobab fruit pulp was evaluated at $20,25,30$, and $37^{\circ} \mathrm{C}$. Sampling was done at hourly intervals over a period of $24 \mathrm{~h}$. Sequential 10-fold dilutions of the culture samples were made in peptone physiological saline solution (8.5 $\mathrm{g} / \mathrm{L}$ of $\mathrm{NaCl}$ and $1 \mathrm{~g} / \mathrm{L}$ of neutralized bacteriological peptone, LP0034, Oxoid Ltd., Basingstoke, UK) and subsequently plated in triplicate onto de Man, Rogosa, and Sharpe agar (MRS; 1.2\% Agar bacteriological, Oxoid Ltd., LP0011 added to de Man, Rogosa, and Sharpe broth, VM986641, Merck KGaA, Darmstadt, Germany). de Man, Rogosa, and Sharpe agar plates were incubated at $37^{\circ} \mathrm{C}$ in GasPack anaerobic jars (Becton Dickinson Microbiology Systems, Baltimore, MD). Colonies on MRS agar were counted, and results were expressed as colony forming units per milliliter (cfu $/ \mathrm{mL}$ ) of L. rhamnosus yoba. The maximal specific growth rates $\left(\mu_{\max }\right)$ for the $L$. rhamnosus yoba cultures were determined using the plate-count data.

\section{Preparation of Probiotic Mutandabota}

Probiotic mutandabota was prepared in triplicate on separate days in Binga district, Zimbabwe $\left(17^{\circ} 36^{\prime} \mathrm{S}\right.$, $27^{\circ} 32^{\prime} \mathrm{E}$ ), using a modification of the traditional process (Ministry of Agriculture, 2001; Mpofu et al., 2014). Village women under our supervision prepared probiotic mutandabota using process steps illustrated in Figure 1. To prepare $2 \mathrm{~L}$ of probiotic mutandabota, $1,570 \mathrm{~mL}$ of cow milk was boiled for about 5 min and cooled to an ambient temperature of $25^{\circ} \mathrm{C}$. Lactobacillus rhamnosus yoba inoculum $(5 \mathrm{~mL})$ that had been propagated in milk with $4 \%$ baobab fruit pulp (as explained earlier) was inoculated into the cooled milk. Next, $63 \mathrm{~g}$ of baobab fruit pulp was added with continuous stirring. This milk with $4 \%$ baobab fruit pulp was left to ferment for $24 \mathrm{~h}$ at 23 to $37^{\circ} \mathrm{C}$, while the growth of the bacterium was monitored. After the fermentation step, $217 \mathrm{~g}$ of baobab fruit pulp and $140 \mathrm{~g}$ of crystalline sucrose were added and mixed for 7 min or until a homogeneous mixture was obtained. Probiotic mutandabota was then ready for consumption. The composition of probiotic mutandabota was $14 \%$ (wt/vol) baobab fruit pulp, $7 \%$ (wt/vol) sugar, and $79 \%$ (wt/vol) cow milk with viable L. rhamnosus yoba cells. In the negative control experiment, all conditions and procedures were the same as in the production of probiotic mutandabota, except for the addition of $5 \mathrm{~mL}$ of autoclaved distilled water instead of the L. rhamnosus yoba inoculum.

\section{Incubation Conditions for Probiotic Mutandabota}

Inoculated milk with $4 \%$ baobab fruit pulp was incubated for $24 \mathrm{~h}$. Because neither electricity nor incubation facilities were available in Binga district, a remote rural area, the vessel with mutandabota was put in the sunlight during the day to absorb maximum heat. At night it was left next to the fireplace in a traditional grass-thatched kitchen (Pinterest, 2013). The preparation temperature was measured using i-button temperature loggers (DS 1922T-FS\#, HQTronics, Dokkum, the Netherlands). One i-button was placed in the fermentation vessel, a second i-button was placed in the open air, and a third i-button was placed in the traditional kitchen. The i-buttons logged temperature at 15 -min intervals over a 24 -h period.

\section{L. rhamnosus Yoba in Probiotic Mutandabota and $\mathrm{pH}$ Measurement}

Lactobacillus rhamnosus yoba was enumerated in probiotic mutandabota and the control experiment (i.e., without added L. rhamnosus yoba). Lactobacillus rhamnosus yoba enumeration was done (i) in the inoculum just before inoculation, (ii) in milk with $4 \%$ baobab fruit pulp just before 24-h incubation $(t=0)$, (iii) at the end of 24-h incubation $(t=24)$, and (iv) just before consumption of probiotic mutandabota. Plating on MRS agar and incubation conditions were the same as explained earlier. Colonies were checked microscopically to confirm absence of yeasts.

The $\mathrm{pH}$ values during preparation of probiotic mutandabota were measured using a combined glass electrode $\mathrm{pH}$ meter (WTW, Weilheim, Germany). The $\mathrm{pH}$ meter was calibrated using standard buffer solutions (Merck, Darmstadt, Germany) at $\mathrm{pH} 4.0$ and 7.0. A sample of probiotic mutandabota was taken from the fermentation vessel and $\mathrm{pH}$ was determined. The $\mathrm{pH}$ was measured (1) at the start of the incubation $(t=$ $0),(2)$ at the end of 24-h incubation $(t=24)$, and (3) in probiotic mutandabota that was ready for consumption. 


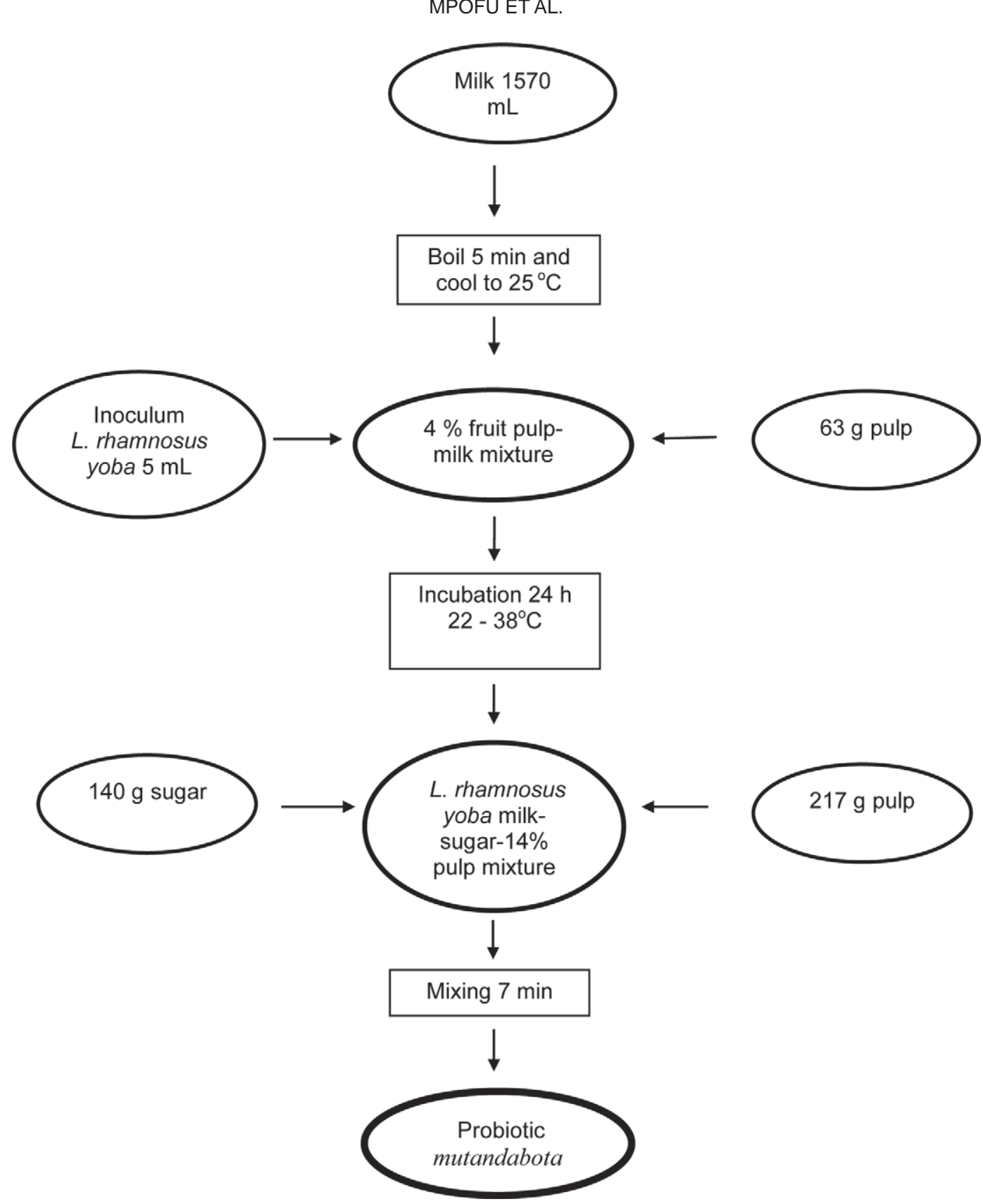

Figure 1. Flowchart for the production of probiotic mutandabota. L. rhamnosus = Lactobacillus rhamnosus.

\section{Statistical Analysis}

The mean values of ingredients and $\mathrm{pH}$ of all samples as well as average levels of $L$. rhamnosus yoba in experiments were compared using a one-way ANOVA. Statistical analysis was done using SPSS 13.0 for windows (Apache Software Foundation, Forest Hill, MD) and Excel (Microsoft Corp., Redmond, WA). Descriptive statistics such as means, percentages, frequencies, and variances were computed and used to describe the data.

\section{RESULTS AND DISCUSSION}

\section{pH Changes During Production of Probiotic Mutandabota}

It is imperative from a health-supporting perspective that probiotic mutandabota contains $L$. rhamnosus yoba in excess of $10^{6}$ viable cells per milliliter at the point of consumption (Shah, 2000; Adikhari et al., 2003). Growth of L. rhamnosus GG and other probiotic lactic acid bacteria in dairy products has been stimulated by 
addition of fruit juice or fruit pulp (Espirito-Santo et al., 2011). In this study baobab fruit pulp was added to milk to stimulate growth of $L$. rhamnosus yoba, and the $\mathrm{pH}$ was monitored to ensure that it remained within the $\mathrm{pH}$ range that allows growth of $L$. rhamnosus yoba. The relationship between final $\mathrm{pH}$ and amount of baobab fruit pulp is shown in Table 1. A fruit pulp content of $2 \%$ gave a $\mathrm{pH}$ of $5.4 \pm 0.1$. This $\mathrm{pH}$ value allowed growth of $L$. rhamnosus yoba but was not enough to sustain growth of the bacterium over a 24 -h period due to substrate limitation. Doubling the amount of fruit pulp to $4 \%$ resulted in a $\mathrm{pH}$ of $4.6 \pm 0.1$. Increasing the fruit pulp concentration above $6 \%$ resulted in a further decrease in $\mathrm{pH}$, which allowed survival of $L$. rhamnosus yoba, but not its growth. The low $\mathrm{pH}$ of the mixture could be attributed to the acidic nature of dry baobab fruit pulp. Airan and Desai (1954) first highlighted the presence of organic acids in baobab fruit pulp. Later reports by Nour et al. (1980) and Vertuani et al. (2002) confirmed the presence of citric, tartaric, malic, succinic, and ascorbic acids in baobab fruit pulp. According to Liew et al. (2005) the optimum $\mathrm{pH}$ value for growth of $L$. rhamnosus is in the range of $\mathrm{pH} 6.4$ to 6.9. The lowest $\mathrm{pH}$ for growth is within the range of $\mathrm{pH} 4.4$ to 3.4 (Helland et al., 2004). Therefore, milk fortified with $4 \%$ (wt/vol) baobab fruit pulp with a corresponding $\mathrm{pH}$ of $4.6 \pm 0.1$ was used for effective propagation of $L$. rhamnosus yoba.

In probiotic mutandabota preparation, the $\mathrm{pH}$ of the milk with $4 \%$ fruit pulp at the point of inoculation was $\mathrm{pH} 4.5 \pm 0.1$. After $24 \mathrm{~h}$ of fermentation with L. rhamnosus yoba, the $\mathrm{pH}$ decreased to $3.9 \pm 0.1$. Organic acids such as lactic acid produced by L. rhamnosus yoba during fermentation could have been responsible for the decrease in $\mathrm{pH}$ value. After all ingredients were added, the final probiotic mutandabota with $14 \%$ fruit pulp had a $\mathrm{pH}$ of 3.5. Such a low $\mathrm{pH}$ ensures microbiological safety of probiotic mutandabota. Most food pathogens do not survive or grow at such a low $\mathrm{pH}$ (International Commission on Microbiological Specifications for Foods, 2002). However, to secure safety of

Table 1. Mean $\mathrm{pH}$ of milk mixed with baobab fruit pulp $(\mathrm{n}=3)$

\begin{tabular}{lccc}
\hline Pulp (\%) & Pulp (g) & Milk (g) & $\mathrm{pH}$ \\
\hline 0 & 0 & 25 & 6.6 \\
2 & 0.5 & 24.5 & $5.4 \pm 0.1$ \\
4 & 1 & 24 & $4.6 \pm 0.1$ \\
6 & 1.5 & 23.5 & $4.2 \pm 0.1$ \\
8 & 2 & 23 & $3.9 \pm 0.1$ \\
10 & 2.5 & 22.5 & $3.7 \pm 0.1$ \\
12 & 3 & 22 & 3.6 \\
14 & 3.5 & 21.5 & $3.6 \pm 0.1$ \\
16 & 4 & 21 & 3.5 \\
\hline
\end{tabular}

probiotic mutandabota, it is necessary to evaluate the risk food pathogens pose to consumers at the point of consumption. The final $\mathrm{pH}$ in the control experiment was also 3.5 .

\section{Temperature Changes During Production of Probiotic Mutandabota}

Temperature is a dominant factor determining the bacterial growth rate $\left(\mu_{\max }\right)$. The $\mu_{\max }$ for L. rhamnosus yoba in milk supplemented with $4 \%$ baobab fruit pulp at $20^{\circ} \mathrm{C}$ was $0.22 / \mathrm{h}$, whereas at $37^{\circ} \mathrm{C}$ it was $0.96 / \mathrm{h}$ (Figure 2). An essential aspect of enabling the propagation of probiotics in a traditional setting, such as the one where mutandabota originates from, is to maintain the cultivation temperature in a physiologically acceptable range without the use of modern means such as electricity for controlled heating. In this study, the objective was to attain a growth rate around $0.6 / \mathrm{h}$. Consequently, the vessel with mutandabota was placed next to a wall in direct sunlight during the day to ensure that the temperature inside the fermentation vessel was as close as possible to optimum growth temperatures of L. rhamnosus yoba. At night it was placed in a traditional Ndebele kitchen near the fireplace. Traditional Ndebele kitchens are built of bricks or mud with a grass thatching (Pinterest, 2013). This makes them well insulated from the hot daytime temperature, which can reach $44^{\circ} \mathrm{C}$, and from the cold night temperature of about $10^{\circ} \mathrm{C}$. In the kitchen, the vessel was placed near a fireplace, where residual heat from the fireplace kept the temperature in the vessel higher than the kitchen temperature.

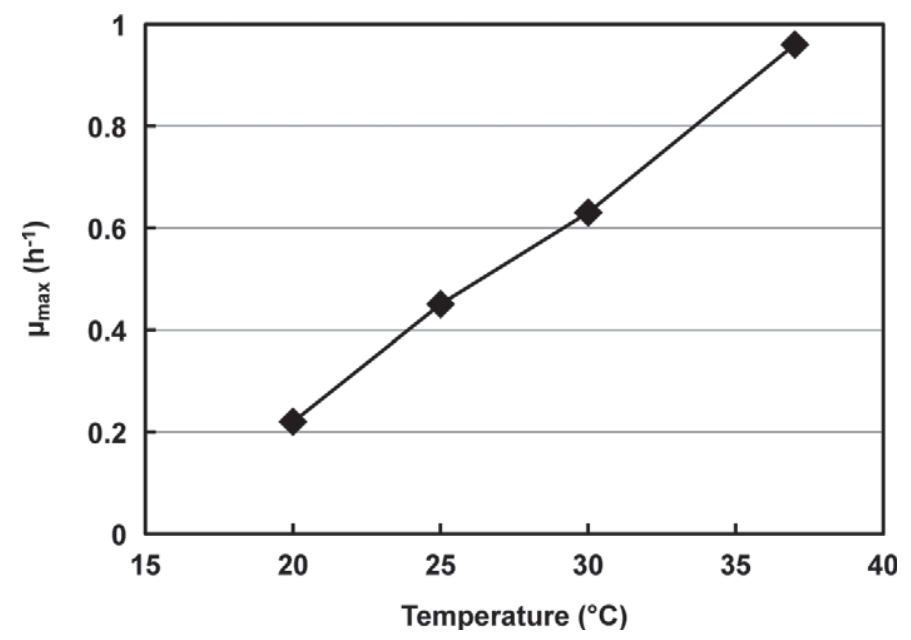

Figure 2. Specific growth rate of Lactobacillus rhamnosus yoba in milk supplemented with $4 \%$ baobab fruit pulp as a function of incubation temperature. 
The mean temperature of the environment and product during the production process of probiotic mutandabota was logged using i-buttons at 15-min intervals over a 24 -h period (Figure 3 ). The incubation started in the morning at $1120 \mathrm{~h}$. The initial temperature in the fermentation vessel was $29.8 \pm 3.8^{\circ} \mathrm{C}$; this was also the ambient temperature because boiled milk was cooled to ambient temperature before inoculation. The temperature rose to reach a maximum of $36.5 \pm 6.7^{\circ} \mathrm{C}$ after approximately $3.5 \mathrm{~h}$, at $1430 \mathrm{~h}$, usually the hottest period of the day in this part of the country. The temperature gradually decreased in the fermentation vessel to a minimum of $22.5 \pm 3.3^{\circ} \mathrm{C}$ after approximately 21 $\mathrm{h}$ from the start. This occurred at around $0700 \mathrm{~h}$. The vessel was removed from the warm kitchen environment at around $0600 \mathrm{~h}$, hence the temperature equilibrated to the environmental temperature outside. The temperature started to increase again to $34.5 \pm 8.5^{\circ} \mathrm{C}$ when the experiment ended after $24 \mathrm{~h}$. Wood and Holzapfel (1995) noted that L. rhamnosus, as a mesophile, grows well at temperatures between 15 and $40^{\circ} \mathrm{C}$.

The temperature in the fermentation vessel stayed above both kitchen and environmental temperature during the day and at night (Figure 2). Thus, putting the pot in an advantageous position during the day and at night enabled attainment of the temperature that favored growth of $L$. rhamnosus yoba. The initial temperature within the kitchen was $27.3 \pm 5.6^{\circ} \mathrm{C}$, the maximum kitchen temperature recorded was $29.4 \pm$ $3.5^{\circ} \mathrm{C}$ after $3.5 \mathrm{~h}$, and the minimum kitchen temperature recorded was $19.5 \pm 3.3^{\circ} \mathrm{C}$ after $19 \mathrm{~h}$. The open environment temperature showed the highest variation

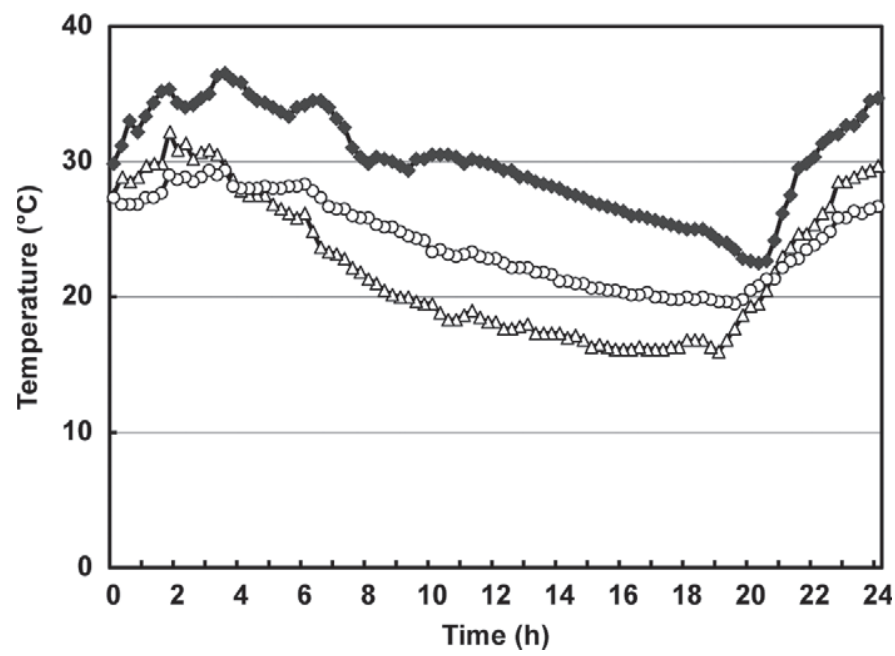

Figure 3. Mean temperatures changes during the production of probiotic mutandabota $(\mathrm{n}=3)$. The temperature inside the product mutandabota (closed diamonds), the ambient temperature outside (open triangles), and the temperature in the kitchen (closed circles) were monitored during a period of $24 \mathrm{~h}$. with a maximum of $32.2 \pm 5.3^{\circ} \mathrm{C}$ after $2 \mathrm{~h}$ and the minimum of $16.0 \pm 1.8^{\circ} \mathrm{C}$ after $19 \mathrm{~h}$. Generally, monthly average high temperature in Binga district ranges from 21 to $31^{\circ} \mathrm{C}$, and monthly average low temperature ranges from 15 to $22^{\circ} \mathrm{C}$ (Worldweatheronline, 2013). This implies that seasonal variations are confined in a narrow range, which allows production of probiotic mutandabota using this procedure throughout the year. However, if this technology was to be applied in other remote, cold regions without electricity, keeping the fermentation vessel close to the fireplace for $24 \mathrm{~h}$ would ensure physiologically acceptable growth temperature for L. rhamnosus yoba.

\section{Enumeration of L. rhamnosus Yoba in Probiotic Mutandabota}

Viable counts of L. rhamnosus yoba in probiotic mutandabota were determined at different stages of the preparation process (Table 2). The milk supplemented with $4 \%$ baobab fruit pulp was inoculated with $L$. rhamnosus yoba at a level of $5.8 \pm 0.3 \log \mathrm{cfu} / \mathrm{mL}$. After $24 \mathrm{~h}$ of incubation at a temperature regimen of 23 to $37^{\circ} \mathrm{C}$ (Figure 3), the viable plate count of L. rhamnosus yoba increased to a level of $8.8 \pm 0.3 \log \mathrm{cfu} / \mathrm{mL}$. This indicates that $4 \%$ baobab fruit pulp was sufficient to support an increase in cell numbers of $L$. rhamnosus yoba by 3 orders of magnitude within $24 \mathrm{~h}$. Arnold et al. (1985) and Chadare et al. (2009) reported proximate composition of baobab fruit pulp on a dry-weight basis as (g/100 g) CP 5.3, fiber 13.7, fat 3.6, ash 4.9, and carbohydrates 74.9. The carbon sources in baobab fruit pulp and full-fat cow milk were apparently enough to support growth of L. rhamnosus yoba. Murray et al. (2001) reported $35.6 \mathrm{~g} / 100 \mathrm{~g}$ (dry-weight basis) simple sugars in baobab fruit pulp. Babu and coworkers (1992) and Kailasapathy and Supriadi (1996) noted that tomato juice and papaya pulp stimulated growth of a related lactic acid bacterium $L$. acidophilus. In the latter case, the growth stimulation was explained by an increased availability of simple sugars, mainly glucose and fructose, and the minerals magnesium and manganese, which are growth promoters for L. acidophilus (Ahmed and Mital, 1990). Minerals reported in baobab fruit pulp included (mg/100 g) iron 9.3, calcium 295, magnesium 90, manganese 0.7 , zinc 1.8 , sodium 2.8, and potassium 1,240 (Osman, 2004). In mutandabota, growth of L. rhamnosus yoba was also supported by milk constituents other than lactose. Moreover, boiling of milk releases some free amino acids that promote bacterial growth (Hekmat and McMahon, 1992). The chosen process with preheated milk provided a practically sterile environment for the growth of L. rhamnosus yoba, and therefore, no competition existed for nu- 
Table 2. Probiotic mutandabota composition and numbers of Lactobacillus rhamnosus yoba at different stages of preparation $(\mathrm{n}=3)$

\begin{tabular}{lcccc}
\hline & \multicolumn{4}{c}{ Stage } \\
\cline { 2 - 5 } & Inoculum & $\begin{array}{c}\text { At inoculation } \\
t=0\end{array}$ & $\begin{array}{c}\text { End of incubation } \\
t=24\end{array}$ & $\begin{array}{c}\text { Probiotic mutandabota } \\
\text { on consumption }\end{array}$ \\
Ingredient & 4 & 4 & 4 & 14 \\
Pulp (\% wt/wt) & 96 & 96 & 96 & 79 \\
Milk (\% wt/wt) & 0 & 0 & 0 & 7 \\
Sugar (\% wt/wt) & $9.3 \pm 0.2$ & $5.8 \pm 0.3$ & $8.8 \pm 0.3$ & $8.8 \pm 0.4$ \\
L. rhamnosus yoba (log cfu/mL) & & &
\end{tabular}

trients with other microorganisms associated with raw milk (Mutukumira et al., 1996; Mpofu et al., 2014). A $\mathrm{pH}$ value of 4.5 , even though suboptimal for growth of L. rhamnosus yoba, allowed significant growth to occur. Sheehan et al. (2007) observed that among lactobacilli and bifidobacteria, L. casei DN-114 001, L. rhamnosus GG, and $L$. paracasei NFBC43338 displayed the highest robustness surviving at levels above $10^{7} \mathrm{cfu} /$ $\mathrm{mL}$ in orange juice $(\mathrm{pH} 3.65)$ and above $10^{6} \mathrm{cfu} / \mathrm{mL}$ in pineapple juice ( $\mathrm{pH} 3.40$ ) for at least $12 \mathrm{wk}$.

To finish the preparation of probiotic mutandabota, crystalline sucrose and more baobab fruit pulp were added and mixed for $7 \mathrm{~min}$. The general practice is that mutandabota is consumed within the first $12 \mathrm{~h}$ after preparation. As shown in Table 2, the viable plate count of L. rhamnosus yoba at the moment of consumption was $8.8 \pm 0.4 \log \mathrm{cfu} / \mathrm{mL}$. Mutandabota is consumed once or twice a day, with servings ranging from 250 to $450 \mathrm{~mL}$ depending on the age of the consumer. As such, a meal of mutandabota delivered the probiotic bacterium in numbers well above the recommended beneficial threshold value (Tamime et al., 1995; Kajander et al., 2008). Recovered L. rhamnosus yoba cells from probiotic mutandabota just before consumption had typical white, round, and convex colonies. Cell morphology was confirmed by microscope. No colony forming units existed on MRS agar that was spread plated with material from the control sample. No yeast cells were detected in probiotic mutandabota and in the control experiment.

\section{CONCLUSIONS}

Probiotic mutandabota was produced at the village level. The amounts of the ingredients in probiotic mutandabota were similar to those in traditional mutandabota, namely 14\% (wt/vol) baobab fruit pulp and $7 \%$ (wt/vol) sugar in full-fat cow milk. Additionally, probiotic mutandabota had $8.8 \pm 0.4 \log \mathrm{cfu} / \mathrm{mL}$ viable L. rhamnosus yoba cells at the moment of consumption. These results show that the criterion for a probiotic food, namely to have a viable cell concentration in excess of $6 \log \mathrm{cfu} / \mathrm{mL}$ of product, was met. The $\mathrm{pH}$ of probiotic mutandabota was $\mathrm{pH} 3.5$, which ensured its microbiological safety. Baobab fruit pulp at $4 \%$ concentration in milk promoted growth of L. rhamnosus yoba by 3 orders of magnitude within $24 \mathrm{~h}$. Unlike the current trend where exotic fruits are used in probiotic dairy food products, in this study an indigenous fruit was successfully used to grow a probiotic strain, thus opening an avenue to exploit indigenous fruits as ingredients in the formulation of locally produced probiotic products. Although this work focused on growth of $L$. rhamnosus yoba in mutandabota, the potential exists to apply this approach on other traditional foods as well, thereby enhancing access to probiotics for communities who might need them most. In conclusion, we have developed a means of generating access to $L$. rhamnosus yoba, a probiotic strain, to the rural population of southern Africa, using mutandabota, a traditional food, with viable L. rhamnosus yoba in excess of recommended daily intake levels.

\section{ACKNOWLEDGMENTS}

The authors thank the Netherlands Organization for International Cooperation in Higher Education (NUFFIC; grant award number CF6631/2010) and Chinhoyi University of Technology (SRC grant number /03/08/10) for financial assistance. We thank Yoba for Life Foundation for providing the Lactobacillus rhamnosus yoba strain and Bert Hafkamp of CSK Food Enrichment (Leeuwarden, the Netherlands) for assistance in supplying the L. rhamnosus yoba. We also thank Melania Dandadzi for field and laboratory work assistance. The enthusiastic participation of farmers in Siyanzyundu, Binga, and Chirenje village, Marondera, Zimbabwe, is greatly appreciated.

\section{REFERENCES}

Adikhari, K., A. Mustapha, and I. U. Grun. 2003. Survival and metabolic activity of microencapsulated Bifidobacterium in stirred yoghurt. J. Food Sci. 68:275-280.

Ahmed, B., and B. K. Mital. 1990. Effects of magnesium and manganese ions on the growth of Lactobacillus acidophilus. J. Food Technol. 27:228-229. 
Airan, I. W., and R. M. Desai. 1954. Sugars and organic acids in $A d-$ ansonia digitata $\mathrm{L}$. J. Univ. Bombay 22:23-27.

Alander, M., R. Satokari, R. Korpela, M. Saxelin, T. Vilpponen-Salmela, T. Mattila-Sandholm, and A. Von Wright. 1999. Persistence of colonization of human colonic mucosa by a probiotic strain, Lactobacillus rhamnosus GG, after oral consumption. Appl. Environ. Microbiol. 65:351-354.

Arnold, T. H., M. J. Wells, and A. S. Wehmeyer. 1985, Khoisan food plants: Taxa with potential for future economic exploitation. Pages 69-86 in Kew Int. Conf. Econ. Plants Arid Lands. G. E. Wickens, J. R. Goodin, and D. V. Field, ed. Allen \& Unwin, London, UK.

Babu, V., B. K. Mital, and S. K. Garg. 1992. Effect of tomato juice addition on the growth and activity of Lactobacillus acidophilus. Int. J. Food Microbiol. 17:67-70.

Chadare, F. J., A. R. Linnemann, J. D. Hounhouigan, M. J. R. Nout, and M. A. J. S. van Boekel. 2009. Baobab food products: A review on their composition and nutritional value. Crit. Rev. Food Sci. Nutr. 49:254-274.

Corcoran, B. M., C. Stanton, G. F. Fitzgerald, and R. P. Ross. 2005. Survival of probiotic Lactobacilli in acidic environments is enhanced in the presence of metabolizable sugars. Appl. Environ. Microbiol. 71:3060-3067.

Esprrito-Santo, A. P., P. Perego, A. Converti, and M. N. Oliveira. 2011. Influence of food matrices on probiotic viability. A review focusing on the fruity bases. Trends Food Sci. Technol. 22:377-385.

FAO/WHO (Food and Agriculture Organization of the United Nations/World Health Organization). 2001. Health and nutritional properties of probiotics in food including powder milk with live lactic acid bacteria. Joint FAO/WHO Expert Consultation on Evaluation of Health and Nutritional Properties of Probiotics in Food Including Powder Milk with Live Lactic Acid Bacteria. Amerian Córdoba Park Hotel, Córdoba, Argentina. WHO, Geneva, Switzerland.

Food and Nutrition Council. 2010. Zimbabwe national nutrition survey: Preliminary findings. Minist. Health Child Welf., Harare, Zimbabwe.

Gaudreau, H., C. P. Champagne, and P. Jelen. 2005. The use of crude cellular extracts of Lactobacillus delbrueckii ssp. bulgaricus 11842 to stimulate growth of a probiotic Lactobacillus rhamnosus culture in milk. Enzyme Microb. Technol. 36:83-90.

Gionchetti, P., F. Rizzello, C. Morselli, G. Poggioli, R. Tambasco, C Calabrese, P. Brigidi, B. Vitali, G. Straforini, and M. Campieri. 2007. High-dose probiotics for the treatment of active pouchitis. Dis. Colon Rectum 50:2075-2082.

Gopal, P. K., J. Prasad, J. Smart, and H. S. Gill. 2001. In vitro adherence properties of Lactobacillus rhamnosus DR20 and Bifidobacterium lactis DR10 strains and their antagonistic activity against an enterotoxigenic Escherichia coli. Int. J. Food Microbiol. 67:207-216.

Grandy, G., M. Medina, R. Soria, C. G. Terán, and M. Araya. 2010. Probiotics in the treatment of acute rotavirus diarrhoea. A randomized, double-blind, controlled trial using two different probiotic preparations in Bolivian children. BMC Infect. Dis. 10:253-266.

Guandalini, S., L. Pensabene, M. A. Zikri, J. A. Dias, L. G. Casali, H. Hoekstra, S. Kolacek, K. Massar, D. Micetic-Turk, A. Papadopoulou, J. S. de Sousa, B. Sandhu, H. Szajewska, and Z. Weizman. 2000. Lactobacillus GG administered in oral rehydration solution to children with acute diarrhea: A multicenter European trial. J. Pediatr. Gastroenterol. Nutr. 30:54-60.

Hekmat, S., and D. J. McMahon. 1992. Survival of Lactobacillus acidophilus and Bifidobacterium bifidum in ice cream for use as a probiotic food. J. Dairy Sci. 75:1415-1422.

Hekmat, S., and G. Reid. 2007. Survival of Lactobacillus reuteri RC14 and Lactobacillus rhamnosus GR-1 in milk. Int. J. Food Sci. Technol. 42:615-619.

Helland, M. H., T. Wicklund, and J. A. Narvhus. 2004. Growth and metabolism of selected strains of probiotic bacteria in milk- and water-based cereal puddings. Int. Dairy J. 14:957-965.

Hojsak, I., N. Snovak, S. Abdovic, H. Szajewska, Z. Misak, and S. Kolacek. 2010. Lactobacillus rhamnosus GG in the prevention of gastrointestinal and respiratory tract infections in children who attend day care centers: A randomized, double-blind, placebo-controlled trial. Clin. Nutr. 29:312-316.

International Commission on Microbiological Specifications for Foods. 2002. Microbiological Testing in Food Safety Management: Microorganisms in Food 7. Springer Sci., New York, NY.

Jyoti, B. D., A. K. Suresh, and K. V. Venkatesh. 2003. Diacetyl production and growth of Lactobacillus rhamnosus on multiple substrates. World J. Microbiol. Biotechnol. 19:509-514.

Kailasapathy, K., and D. Supriadi. 1996. Effect of whey protein concentrate on the survival of Lactobacillus acidophilus in lactose hydrolysed yoghurt during refrigerated storage. Milchwissenschaft 51:565-567.

Kajander, K., E. Myllyluoma, M. Rajilicstojanovic, S. Kyronpalo, M. Rasmussen, S. Jarvenpa, E. G. Zoetendal, W. M. de Vos, H. Vapaatalo, and R. Korpela. 2008. Clinical trial: Multispecies probiotic supplementation alleviates the symptoms of irritable bowel syndrome and stabilizes intestinal microbiota. Aliment. Pharmacol. Ther. 27:48-57.

Kankainen, M., L. Paulin, S. Tynkkynen, I. V. Ossowski, J. Reunanen, P. Partanen, R. Satokari, S. Vesterlund, A. P. Hendrickx, S. Lebeer, S. C. De Keersmaecker, J. Vanderleyden, T. Hämäläinen, S. Laukkanen, N. Salovuori, J. Ritari, E. Alatalo, R. Korpela, T. Mattila-Sandholm, A. Lassig, K. Hatakka, K. T. Kinnunen, H. Karjalainen, M. Saxelin, K. Laakso, A. Surakka, A. Palva, T. Salusjärvi, P. Auvinen, and W. M. de Vos. 2009. Comparative genomic analysis of Lactobacillus rhamnosus GG reveals pili containing a human-mucus binding protein. Proc. Natl. Acad. Sci. USA 106:17193-17198.

Kort, R., and W. Sybesma. 2012. Probiotics for every body. Trends Biotechnol. 30:613-615.

Lacroix, C., and B. Mollet. 2007. Fermentation technologies for the production of probiotics with high viability and functionality. Curr. Opin. Biotechnol. 18:176-183.

Liew, S. L., A. B. Ariff, A. R. Raha, and Y. W. Ho. 2005. Optimization of medium composition for the production of a probiotic microorganism, Lactobacillus rhamnosus, using response surface methodology. Int. J. Food Microbiol. 102:137-142.

Mack, D. R., S. Michail, S. Wei, L. McDougall, and M. A. Hollingsworth. 1999. Probiotics inhibit enteropathogenic Escherichia coli adherence in vitro by inducing intestinal mucin gene expression. Am. J. Physiol. 276:941-950.

Ministry of Agriculture. 2001. Report on Postharvest Fruit Handling Practices and Traditional Processing of Indigenous Fruits. Dept. Res. Spec. Serv., Minist. Agric., Harare, Zimbabwe.

Mpofu, A. A. R. Linnemann, M. J. R. Nout, M. H. Zwietering, and E. J. Smid. 2014. Mutandabota, a food product from Zimbabwe: Processing, composition and socio-economic aspects. Ecol. Food Nutr. 53:24-41.

Murray, S. S., M. J. Schoeninger, H. T. Bunn, T. R. Pickering, and J A. Marlett. 2001. Nutritional composition of some wild plant foods and honey used by Hadza foragers of Tanzania. J. Food Compost. Anal. 14:3-13.

Mutukumira, A. N., S. B. Feresu, J. A. Narvhus, and R. K. Abrahamsen. 1996. Chemical and microbiological quality of raw milk produced by smallholder farmers in Zimbabwe. J. Food Prot. 59:984-987.

Nour, A. A., B. I. Magboul, and N. H. Kheiri. 1980. Chemical composition of baobab fruit (Adansonia digitata L.). Trop. Sci. 22:383388.

Olivieri, F., S. Semproli, D. Pettener, and S. Toselli. 2008. Growth and malnutrition of rural Zimbabwean children (6-17 years of age). Am. J. Phys. Anthropol. 136:214-222.

Osman, M. A. 2004. Chemical and nutrient analysis of baobab (Adansonia digitata) fruit and seed protein solubility. Plant Foods Hum. Nutr. 59:1-5.

von Ossowski, I. V., J. Reunanen, R. Satokari, S. Vesterlund, M. Kankainen, H. Huhtinen, S. Tynkkynen, S. Salminen, W. M. de Vos, and A. Palva.2010. Mucosal adhesion properties of the probiotic Lactobacillus rhamnosus GG SpaCBA and SpaFED pilin subunits. Appl. Environ. Microbiol. 76:2049-2057. 
Pinterest. 2013. African Traditional huts. Accessed Jun. 302013. http://pinterest.com/WeetaK/african-traditional-huts/.

Reid, G. 2008. How science will help shape future clinical applications of probiotics. Clin. Infect. Dis. 46:S62-S66.

Rinkinen, M., K. Jalava, E. Westermarck, S. Salminen, and A. C. Ouwehand. 2003. Interaction between probiotic lactic acid bacteria and canine pathogens: A risk factor for intestinal Enterococcus faecium colonization. Vet. Microbiol. 92:111-119.

Ruszczynski, M., A. Radzikowski, and H. Szajewska. 2008. Clinical trial: Effectiveness of Lactobacillus rhamnosus (strains E / N, Oxy and Pen) in the prevention of antibiotic-associated diarrhoea in children. Aliment. Pharmacol. Ther. 28:154-161.

Sandholm-Mattila, T., S. Blum, J. K. Collins, R. Crittenden, W. de Wos, C. Dunne, R. Fondén, G. Grenov, E. Isolauri, B. Kiely, P. Marteau, L. Morelli, A. Ouwehand, R. Reniero, M. Saarela, S. Salminen, M. Saxelin, E. Schiffrin, F. Shanahan, E. Vaughan, and A. von Wright. 1999. Probiotics: Towards demonstrating efficacy. Trends Food Sci. Technol. 10:393-399.

Shah, N. P. 2000. Probiotic bacteria: Selective enumeration and survival in dairy foods. J. Dairy Sci. 83:894-907.

Sheehan, V. M., P. Ross, and G. F. Fitzgerald. 2007. Assessing the acid tolerance and the technological robustness of probiotic cultures for fortification in fruit juices. Innov. Food Sci. Emerg. Technol. 8:279-284.
Tamime, A. Y., V. M. E. Marshall, and R. K. Robinson. 1995. Microbiological and technological aspects of milks fermented by Bifidobacteria. J. Dairy Res. 62:151-187.

Tuomola, E. M., A. C. Ouwehand, and S. J. Salminen. 2000. Chemical, physical and enzymatic pre-treatments of probiotic lactobacilli alter their adhesion to human intestinal mucus glycoproteins. Int. J. Food Microbiol. 60:75-81.

Valík, L., A. Medvedová, M. Čižniar, and D. Liptáková. 2008. Characterization of the growth of Lactobacillus rhamnosus GG in milk at suboptimal temperatures. J. Food Nutr. Res. 47:60-67.

Vertuani, S., E. Braccioli, V. Buzzoni, and S. Manfredini. 2002. Antioxidant capacity of Adansonia digitata fruit pulp and leaves. Acta Phytotherapeutica 2:2-7.

Whorwell, P. J., L. Altringer, J. Morel, Y. Bond, D. Charbonneau, L. O'Mahony, B. Kiely, F. Shanahan, and E. M. Quigley. 2006. Efficacy of an encapsulated probiotic Bifidobacterium infantis 35624 in women with irritable bowel syndrome. Am. J. Gastroenterol. 101:1581-1590.

Wood, B. J. B., and W. H. Holzapfel. 1995. Genera of Lactic Acid Bacteria. Blackie Acad. Prof., London, UK.

Worldweatheronline. 2013. Average High/Low Temperature for Binga, Zimbabwe. Accessed Jun. 30, 2013. http://www.worldweatheron line.com/Binga-weather-averages/Mashonaland-Central/ZW.aspx. 